\title{
3. INDUSTRIAL DESIGN AND CONTEXTUALISM: THE APPLIED ARTS CONSTITUENT/ CURRICULUM IMPERATIVES IN DESIGN PRACTICE AND EDUCATION
}

\author{
Obasuyi Osa-Francis Efer ${ }^{106}$
}

\begin{abstract}
This paper examined the Curriculum imperatives of Industrial design education and the Contextualism of the principles and practice of disciplines such as Applied Arts and Industrial Design viz-a-viz their constituent and contextual roles and place in design practice/ Industry. The issue of contextualism as it relates to Design and the Applied Arts according to DeRose, K. (2009) would seem to mean a collection of views, theories, principles or philosophy of Design / applied Arts which seems to emphasize the context in which the action principles or purpose of design is understood relative to such a context. ie. In Design, the principles and practice of Applied Arts / Design disciplines (such as in Architecture) for example, contextualism refers to that theory of design in which modern / contemporary designs (buildings, products or structures) are harmonized together with the contemporary design ideals, forms and characteristics peculiar to modern ways/styles of living. (Jencks, 2002).
\end{abstract}

This informed the need and thrust of this paper which was predicated on the consideration of contextualing such a role/place of the Applied Arts as a constituent of Design and spotlighting it to be innately and intrinsically connected to the resultative man-made material culture and society. The paper also seeks to establish that the principles and practice of Design education emphasises the Teacher-learner relationship which is aimed at imparting credible problem solving skills and initiatives such as drawing, drafting (draught-manship), modeling or sculpting (in clay or industrial plasticine) styling and prototype creation (realized by moulding/shaping of the clay material to assume any contour, shape, form or topology of the given object) in ordeer to achieve that innate context and desire for the perfect product so designed. This paper recommends that for any design to succeed it must emplace (strictly) a well articulated Industrial Design Curriculum which elucidates those Applied Arts principles and practice as a constituent/major component part in the Design process of manufacture of any given design initiative.

Key words: Algorithmic / Heuristic Approaches, Contextualism, Design Curriculum/ Education, Ideation, Industrial Plasticine, "Partipris", Polymer Clay

\section{Introduction}

What has come to us today to be known as the profession/discipline of industrial design began with the "spark" that was triggered off by the monotony of form and aesthetics of mass produced goods during the industrial revolution of the 1860s. The very foundation of craft and craftsmanship which was the bedrock and springboard from which innovation, and the start of the Age of inventions got its roots, gradually gave way to a revolution of the manufacturing of goods and products being "churned out" of the Assembly line, like "lifeless" and cold "effigys" of what the machine age, became known for. The original role and place of craft and craftsmanship, and artistic traditions of the applied Arts,

\footnotetext{
${ }^{106}$ Senior Lecturer PhD., University of Benin, from Benin City, Nigeria, email: yandref201384@gmail.com
} 
coupled with the role of custom- made, hand-crafted goods (which were the hallmark of masterpieces of the craft and time honored tradition of the Middle Ages,) were quickly swallowed up by the Assembly line serial production methods of mass produced goods for the mass market. The era of consumerism and mass production began as a result. (Archer, 1974). The contextualism of the Applied Arts as a component and compulsory ingredient in its original role and place in craft and, artistic traditions, has helped to highlight the very Nature and context for which the old traditional craft/craftsmen of the Middle Ages became known for. That generation represented the 'Classical Age' of custom-made products that became "Masterpieces" in their own right. This was the singular context for the setting up of the New Movement of Industrial Designers who sought to emplace those ideals at the birth of this New Profession in the late 1800s. (Lucie-Smith, 2001).

So saw the birth of a New profession called industrial Design between 1800 - 1866 (to be precise). Where a group of arts and craft practitioners came together to form what became known as the Arts and Craft movement Spearheaded by the British artist/architect - William Morris. His works and activity in graphic Design, textile design and architecture were so prolific that his printing press (the kelmscott Press) became synonymous with the arts and craft movement. These and the achievement of others like him became the spring board for the take off of the new profession. The issue of its contextualism (as it relates to the Applied Arts and Design) would seem to mean, those collection of views principles, theories or philosophy of Design /Applied Arts that seems to emphasize the context in which the actions, principles or purposes of design is understood relative to such defined context (Beyer et al., 1998). In architecture for example, according to Jencks (2002) who proposed that contextualism represents that theory of design wherein modern/contemporary Architectural designs (buildings, structures or even products) are harmonized with contemporary design ideals, principles and forms, characteristic/peculiar to modern ways of Todays living and lifestyles.

\section{Contextual relevance of Industrial design as a Profession}

Noblet, (1993) emphasises that the meaning and context of industrial design as a profession dwells on the exploration and study, form and function of the intended design initiative with a focus on the meaning and connection between the product, the consumer and the environment in which the product is to function or intended to be used. He continued by saying that industrial design is that professional service aimed at creating and developing ideas and concepts tailored to specification of products that optimizes the function, value (quality, aesthetics and beauty) i.e. the appearance and look of the product in a context that accedes to the mutual benefit and satisfaction of both the consumer and society on the one hand, and the manufacturer and economic benefit/ (put within the context) of the development of society on the other.

There could be a more precise way to look at design from the contextual point of view of pragmatism and realism which according to Coelho (2011) who 
says that "Design could be considered to be that process of taking something (an object, devise or a system) from its "existing state" (the intended object of Design needing a new birth, renewal, recreation or reintroduction) and moving it to a "preferred state". This description of design perfectly fits the context and conception or belief to which I subscribe to in more ways than one. For example, this definition contextualizes the invention or creation of a totally whole new range of goods, services and systems that were hitherto non-existent.

It could also be ascribed to a situation where design is applied to an existing state of being of a product that needs reintroduction, or needs to be Rebranded or improved upon and given a totally new outlook or given a "breath of fresh air" from the original state of the product needing a redefinition of its look, form (make-up,) Morphology, shape and size. As it is transformed to the preferred state of the final finished look of finesse, perfect beauty and aesthetic elegance. Archer (1974) amplifies that opinion and that of the school of thought that says that: "Design in its broader perspective could be defined singularly and severally as the creation of a system, or goods/services, a blue print, an engineering drawing or an object intended to accomplish set targets that satisfies defined goals/objectives, which in turn is intended to meet with specific needs or fill up the avoid in any given/particulate environment. It (design) could also be described as the application of a given set of parameters which tends to satisfy a given set of objectives, standards and requirements in the hope and attempt at creating or bringing to being, a new or Novel creation (or being) in the form of a new design entity. Barnwell (2011), describes Design as a "process of prespecified and preplanned actions, that presents such a process of design as an activity which involves a series of carefully scheduled actions, taken during and after the process of designing to bring to being or fruition an intended design initiative.

\section{Contextual relevance of the Applied Arts in design / Engineering processes}

The contextual relevance of industrial design (or design) could be compared to the use of both the applied arts and applied science (and their unique/industrial principles) to improve the aesthetics (beauty), form, ergonomics, (the man - machine interrelationships) which enhances and improves the functionality and or usability of the given product or service. The contextual role of design as a discipline/profession viz-a-viz that of the Applied Arts according to Price (2008), is to help create and bring to life acceptable design objects/solutions aimed at resolving the problems of form, functionality, usability, marketability, brand development/evolution and the overall sales potentials of the given product. The Applied Arts and Design focuses principally on the "aesthetics" and the "user-interface" aspects of the manufactured product, that gives it that extra edge and potential for consumer patronage over and above its competing rivals.

Arther (1974) and Barnwell (2011) jointly and severally acceded to the fact that the term design is more often than not associated with the contextual 
ideas and principles of the applied arts as could be evidenced by the teachings and works of Ramond Loewy, at the Bauhaus and Ulm school of Design in Germany. They also proffered that Design viz-a-viz Applied Arts is or have become constituent ingredients in the engineering process. Deducing from the above, however is the obvious and more accepted view (or belief) that engineering is considered a "science", (just like in the late 1800s when machine manufactured goods were considered scientific inventions wayback then). Nevertheless, there comes along the question and the contextual argument even today, of what is considered science in the first place? This situation could be better explained by the following two analogy's of distinction; as posited by some scientists working at the Rank Xerox corporation lab in America; who made the distinction of design versus science/engineering thus; that one could be described as "craft and ingenuity" put against "beauty and the aesthetic sentiments" that appeals to human nature and soul, (which represents design) and the other referred to as "moving atoms" i.e. the pure physical sciences of engineering.

\section{Contextual relevance of Industrial Design Curriculum in Design Education. General thrust, Philosophy, aims and Objectives of an Industrial Design Curriculum}

The general thrust philosophy aims and objectives of a well-articulated industrial Design course/ Programme must engender and reflect the following philosophical aims and objectives of a contemporary and articulate industrial design curriculum policy objectives which is embodied by the ensuing discourse on the subject matter under review. According to Manea (2015) who states that "there has to be an integrated approach to creating the arts education curriculum and pedagogy". This approach she says will help Facilitate a way of constructing and Experiencing academic knowledge that is rewarding in such a way that it engages participants imaginatively, emotionally, volitionally and cognitively; while at the same time helping to influence/ "impact both the individuals and the communities concerned aesthetically and culturally". In another case scenario, concerning the strategic development of Arts curriculum for students, Manea (2016) also proferred a graphical model, where she stated that "a reflection upon a graphical model of advancing a $21^{\text {st }}$ century educational perspective, is figuratively situated at an intersection of the 3(three) circles of Truths. Namely:

- Knowledge (what we know)

- Skills (how we use and apply what we know) and

- Character (how we engage with the world).

In the graphical model she says "the three intersecting circles represents three domains of educational intent that all together integrates in a larger circle called Meta-Cognition".

(A) General Philosophy of an industrial Design based curriculum The philosophy of the application and usage of whatever innovations is involved in the new and more reliable methods of curriculum to be employed according 
to Pautler (1976), should be based upon a tangible program philosophy and objectives. The developer of such a program philosophy should be able to interpret national, state; individual/student philosophies and other human engagement objectives. Such course/program philosophy and objectives must also be consistent with the school and departmental goals, targets and objectives. In curriculum planning for instance, the following parameters should be considered:

i. The Nature of the students/learners

ii. The learning process (School time and learning environment, time-tabling etc)

iii. Facilities, material and techniques of instruction

iv. Various curricula methods and approaches (Methodological approaches)

v. Contemporary Industrial/Technological and scientific trends/developments and awareness.

The issue of restructuring a course programme for any field of study or discipline at that, must first and foremost clearly spell out the objectives of what the programme intends to achieve; in terms of end-results or expected societal roles to be performed by these graduates/graduands. To this end the issue of developing a curriculum for an industrial design programme might be seen to be a rigorous one and therefore requires competencies that one thinks does not abound readily. This is because most of what the present crop of Educators implements are programmes of a teacher education that provide instructions in units or course development only (in most cases) and not on curriculum development. So the serious issues of an articulate curriculum is seldom raised. The understanding of curriculum development isn't just about doing something, differently, it is about doing something based on an agreed social purpose and need and therefore that attempt should be able to keep up with the changing times and events of the rest of the world technologically.

The issue of developing an industrial design curriculum requires a wellgrounded knowledge in the discipline as well as be abreast with the knowledge and understanding of the student/learner and how the learning and learner environment works. The curriculum developer needs to know more about change or changes, the change process and the various factors that influences such change/s. There is need for a more balanced effort to deal with the three principal elements of curriculum development which are:

- The CONTENT of the area or discipline

- The SOCIETAL FRAME WORK in which the program functions and lastly,

- The HUMAN or PERSONAL needs component

\section{(B) Specific Objectives of an Industrial Design Based Curriculum}

A Curriculum for industrial Design discipline, according to Devore, P. et.al. (1980) should be structured to reflect the following specific target objectives:

i. Provide specialized, Technology-based professional education aimed at producing highly skilled professional Designers capable interpreting and synthesizing problem situations, and providing solutions to complex technical 
/technological problems in the field of Technical Aesthetics, and Product Design.

ii. Develop the students ability in areas of specialist skills acquisition in Design and other Design related fields as well as acquaint them with the appropriate technological "know-how", and skills training that they can apply effectively when there comes the need for the application of these acquired skills, which will be tested on their encounter with problem-solving exercises in industrial design and other related problems, usually associated with defective designs.

iii. Develop students understanding and highlight awareness of the place of social-cultural norms and values of their immediate environment. In furtherance of the acquisition of the above objectives, an attempt should be made to align the contemporary classroom skills with a broader/sharper understanding and effective utilization of their theoretical educational experiences.

iv. Develop student's ability to understand the elements and principles of industrial design as well as design methods and methodology, and be able to synthesis appropriate information to produce effective designs and prototypes as end results.

v. Develop student's ability (upon graduation) to be able to provide appropriate solutions to the technological, economic and aesthetic problems of society.

vi. Develop student's ability to relate to their clients and their community. This will enable them communicate better, their intended innovations or inventions with the sole aim of positively influencing attitudinal/behavioural change and taste in product cosumership (sales and purchase). This being an appropriate medium and tool for effectively influencing change in societal values.

\section{(C) COURSE CURRICULUM:-Developmental approaches}

In order to develop curriculum, one must be able to determine what skills/professions the students who complete such a course should be able to perform and under what condition they should be able to perform such skills and how well they should be able to do this. Most curriculum developers have adopted the "INDIRECT" or "DISCIPLINE" Approach. In other words, the structure and content of acknowledged disciplines that has been found to work even under the most sever of conditions, is recommended to be used in the design of such curricula/programmes. Further still the other commonly used method is the Indirect or the so called "cut-and- paste" approach. The qualities of this approach is that one takes the best elements of a variety of similar curriculum and puts them together to form another or to form a new curriculum.

A third approach, which is also the Indirect approach, employs the design of a program based on a combination of past educational and life experiences. As can be seen above, all of the indirect approaches provide useful information, but are not finely-tuned actually to deal with the students present and future roles/needs. So, what is needed or required is the "DIRECT" APPROACH. The direct approach is an approach that ensures that relevant content that's in tune with the industrial/technological reality of the time is included. Suggestively supporting this view Paulter (1976) said that the immediate and future needs of the students must be analysed to determine the areas of competences they need 
to acquire such skills. As both students and societal needs also must be analysed to determine the skills and capabilities needed by students that is also relevant to societal needs and problem resolution. Frynier (1973) in his work suggested that a curriculum developer should also analyse what knowledge, skills and attitude/individual needs that are required in order to maintain, the standards by so doing optimize themselves and society at large.

Supportive to the above, it should be noted straightway that the trend of adopting either or both the "REAL TASK" or "COMPETENCY" BASED methods (types) of curriculum development systems, does not have a "hard and fast rule". For information purposes, the Task-Based curriculum development system requires the synthesis of the task, analysis and research by psychologists, educators and the total systems approach to the curriculum designed to ensure it is utilized in a large scale. The "TASK-BASED" curriculum development system, as its first step is aimed at identifying the life roles to which the curriculum will be directed i.e. the present and future roles of student are considered. With specific roles and competencies within these roles that are relevant to the curriculum clearly highlighted.

Also in the Task-based process of curriculum development the developer must identify specific Roles/Tasks, and these Roles broken down to more specific elements called TASKS. A task therefore could be said to be the smallest unit of activity within a role. This task should involve activity, time, and have a purpose in relation to the role and should culminate at a logical ending point. Sources of information for identifying tasks may include, the developer's own personal experiences, or from persons who are knowledgeable or competent in each of the life roles so chosen. Literature on the various roles could be consulted. If the life roles are emerging ones, stimulating the roles may be of help. Tasks so identified should be stated in action form. (Devore et al., 1980).

It is also very vital to consider this next step. That is to "VALIDATE TASKS". This means checking the analysis process carried out in the previous/early stages of development. This involves several techniques, for example, the survey of the actual person's real life role, or observation of the person carrying out such roles. This is to determine if the tasks identified are appropriate. Simulation too could also be of use. Others stages still worth mentioning include the determination of such tasks for its viability and need to be included in the curriculum. Also there is the detailing of tasks, such as identifying the steps required for performing each tasks, the sequence for doing the tasks, the critical points to be encountered in completing such tasks, attitude needed for its successful completion. The cognitive processes, such as problemsolving, analysis and evaluation should be identified and linked with the appropriate steps. Manipulative Skills and knowledge also needs to be identified. It is also very necessary to write behavioural objectives; like-what the person should be able to do under what conditions it should be carried out or done. What is the quality of performance expected to be exhibited and so on. Then start a final Design of the course/programmes. First and foremost, its 
design should be based on the utilization of all the tasks, data and behavioural objectives so gathered. Finally, it is important to evaluate the resultant curriculum proper. This relates to the prior steps taken in the developmental process. The evaluation information should be collected as one progresses through the developmental processes. With these and consequently a follow-up of the impact of the course/programmes developed it is easy to determine the strength and weakness of such an endeavour or the ensuing/resultative curriculum.

\section{Applied Arts as a Constituent of Industrial design}

The contemporary achievements and the influences of the Applied Arts in Design could be largely attributed to the industrial and Applied Arts constituent /components and aspects, which includes, Branding, Styling, Bionics and Ergonomics to mention a few. Industrial design utilizes the Applied Arts, applied sciences and pure sciences in the development and improvement of any given product as it accentuates the qualities of beauty, aesthetics, design, ergonomics (Man-machine Relationship or handling), functionality and/or its usability and ultimate potential marketability. A few of the related fields/discipline which reflects these constituent/ component of the applied arts and industrial design are: Graphic Design, Products Design, Interface design, Transportation/Automobile design, Visual Design, Web Design, Urban Design, Architecture, Communication/Information Design, Computer Science and Technology etc.

\section{INDUSTRIAL DESIGN: APPLIED ARTS AND ITS CONSTITUENT PARTS}

(1) THE CONSTITUENT ASPECT OF IDEATION OR CONCEPTUALIZATION

Design concept (ideation or conceptualization) could be said to mean, an understanding, belief or a system that is borne out of, or in the mind, either from or by experience, reasoning and/or imagination of the given individual. It could also be said to be a generic or basic form of abstraction or mental impression of a particular set of ideas or ideology of instances or occurrences in real life or a contrived/imaginative world. (Jonson, B. 2005). It could also be called a notion or an abstract or general idea inferred or derived from specific or simulated case scenarios. Deducing or stretching that further, therefore, conceptualization according to Morris, R. (2009) Ibid; could mean the invention or contrivance of an idea and sometimes the formulation of this idea mentally and sometimes ensuring it becomes a reality physically. It could also mean the process of the formulation, of a proposed form, or thing or a phenomenon.

\section{(2) THE CONSTITUENT ASPECT OF SKETCHING:}

Sketching is the basic, rudimentary/fundamental stage in the design process and design endeavour. It could also be called drawing, drafting, draughting (draught-manship) or visualization/visuals. Some of these terms are used interchangeably at the prescribed stages of the design life span of a product or service. In the Traditional / conventional Arts perspective Sketching could be 
referred to as an art or applied graphic design work that is executed with design tools such as graphite, pencils, pen and ink, coloured markers, pastel, gouache poster colours or carried out directly on design compliant/enabled computers e.g. the use of computer software applications such as designs done using Element 3D video co-pilot, Auto desk Maya, Alias software, Adobe After Effect, MAXON Cinema 4D, e.t.c.

Most of the contemporary design sketching and technological applications has long overtaken the old hands-on traditional/conventional drawing/sketching techniques. At other times, the Design process might even just eliminate altogether the 2D paper sketching stage and present the 3D model of the intended product in 3Dimension using materials such as kaolin clay, Plasticine, Styrofoam, Wax or better still using the New and Contemporary 3D printing technique, that is making the rounds and creating Rave reviews right now in design technology and manufacturing industry (Goldschmidt, G. 1991). Furthermore, a sketch more often than not also implies or refers to loosely drawn art works or 2D drawing, were the sketch is used to a greater or lesser degree as a means for registering the intended work-able solution of the idea or concept derived from the original concept base.

\section{(3) THE CONSTITUENT ASPECT OF MODELING}

According to David et al. (1982), Modeling as a process in the design, development and production of new products, is brought about by professionals such as craft- workers, designers and engineers who rely on the ingenuity, and conceptual intuitiveness of the Applied artists, sculptors, architects, graphic designers and visual display experts (and of course production/mechanical engineers) who helps bring to life the new product so desired. In the study of design processes and procedures (especially that of modeling and product manufacture/production,) there is what is called the design Techniques of modeling and styling:- Modeling in Design is that act of Creating /Reproducing design initiatives using the 2D initial concept and translating this into 3-D dimension objects using clay (Kaolin), polymer clay, industrial Plasticine, Styrofoam or wax and other more adaptive materials for Design and modeling.

(i) CLAY MODELING (Design and Styling)

Clay and its uses in the design process/endeavour is representative of any soft and malleable substance or material often used in the actualization or for the realization of the form or morphological structure, make-up or buildup of the intended product. For industrial design purposes, there are various types of clay varieties or malleable substances that could be used in designing, building and sculpting of products or systems.

\section{(ii) MODELING: USING INDUSTRIAL PLASTICINE AND POLYMER CLAY}

This is an industrial modeling material, mainly used in the automotive design industry. Industrial plasticine's composition is wax-based and made up of calcium salts and principally calcium carbonate, petroleum Jelly, a long chain of aliphatic acid (stearic acid). It is non-toxic, sterile, soft, malleable and does not dry up on exposure to air. It is made of wax which has a chemical make-up that 
contains sulphur, a yellowish substance with an unpleasant smell found in rock formations usually mined from the earth. It is the sulphur that gives plasticine, the characteristics smell its known to have. It is a soft, elastic and malleable substance usually associated with children's toys and very popular with animation/animators of children films/movies and also in the motor building industry.

\section{(iii) MODELING: POLYMER CLAY}

This is a modeling material that does not shrink or change its shape during the process of extreme heating. Even it it's called clay, it does not necessarily contain any clay materials. Polymer clays are those modeling materials that exhibit qualities of static form from shape to shape, frame by frame and section by section. According to Norman (2002) who states that "Polymer clay is that clay which is made up of a synthetic compound consisting of large molecules of clay compounds, which are linked in a series of repeated simple monomers, which combines several monomers to form a polymer or a polymeric compound".

\section{(4) THE CONSTITUENT ASPECT OF DESIGN, DEVELOPMENT AND STYLING}

The very essence of the development of the design process begins with the acquisition of a viable or credible conceptual idea that has or is a result of a lot of research (logistics, resources, analysis) effort aimed at generating or providing the desired design solution to a given design initiative. As stated earlier above, the design proper begins with the applied artist or industrial designers, putting into 2D visual representational display, images of the various or individual conceptual ideas so arrived at. This conceptual image is presented in full colour 3D visual representation of what the real product would look like. Sometimes an accompanying mock-up of a 3D model or prototype goes with the $2 \mathrm{D}$ visual representation.

Before any product model is launched, computer models are made sometimes in the ratio $1: 4$ or $1: 1$ are built to get an impression of the final product. They could be created or crafted in clay, plasticine or Styrofoam as the case maybe. (Rosenburg et al., 1995). In all of these design efforts, the role of computer Technology and computer aided design CAD/CAM/CAF and all of its applications cannot be overemphasized. The computer applications and software packages discussed earlier like the Element 3D Video co-pilot, Autodesk Maya, Adobe After effect, Alias design packages, and MAXON Cinema, 4D to mention a few are some of those design tools employed in the actualisation of the design initiative. So the term- "STYLING" or design styling or computer-aided styling comes to the fore. (Norman, 2002).

\section{STYLING (OR DESIGN STYLING)}

According to David, F. W. et.al (1982) Ibid, who says that all the design concepts. and 2-D visuals so realized are translated (or transformed) into 3D digital imaging/surface modeling to ensure that the 3D models so developed meets with the Aesthetic requirements and specifications of the designers expectation, as well as meets with all the engineering and manufacturing 
requirements. Styling as a technique in the design process, ensures that both the technical as well as the Aesthetics components harmonises for the optimal utility, form and function of the intended design/product. Tools mostly used in styling by product engineering/styling team are Autodesk, Alias and ICEM SURF computer software application tools. The styling production team often consists of the chief industrial designers, interior designers, and engineering experts. In some cases all three roles are collapsed into one.

\section{(5) DESIGN CONCEPT: EXECUTION AND PRODUCTION. Design and Production}

In the execution or completion of a design initiative certain elements and universal steps taken to ensure the actualization of the design objective.

Digesting that further, the approaches adopted before, during and after the design, process begins, are enumerated in the following simple algorithmic/sequential step by step Design approach. This is consistent with the rational model and method of Design Development/Execution (Morris, 2009).

Examples of these Algorithmic (Sequential Step by Step) Process includes:

\section{(A) Pre-production stage of Design}

- Design brief which could also be called "partipris" This is the early or (beginning) statement of the Design goals, targets and objectives and all of what the Design project is made of, contains or intends to achieve and look like. Its target goals/objective.

- Analysis: This involves the analysis of the prevailing circumstance or status of the product in question. The prevalent issues (pro and cons)

- Investigative Research - search for similar design solutions or for related design analogys and also for alternative initiatives.

- Specification or Narrowing down to probable or possible options while specifying design requirements and product design specification as to form, shape, colour, dimension, weight, existing final state whether liquid solid, paste, viscous or Amorphous and so on.

- Problem-solving: This is the actual execution stage of conceptualization and documentation in 2D and 3D of the Design solution or initiative. Here is where all the Artistic, modeling, styling (computer styling, Rendition and production) prototype production and final fabrication of the real product all come to a climax.

- Design during production: Design development, improvement, amendment and enhancement of the chosen design solution/initiative to ensure it meets with the desired Design objectives.

- Testing, functionality and usability: of the product so achieved or designed.

\section{(B) Post Production Stage of the Design}

- Post manufacture feedback from which future designs and successive models might emanate.

- Implementation: Introduction of the product into the preferred environment for which it is to be used or function. 
- Evaluation and conclusion: A summary of all the Design processes and the results achieved there from to act as a guide for future improvements.

- Redesign: Any or all of the design process might be repeated with corrections for earlier errors made.

\section{Conclusions}

The evolution of most innovative discoveries in science and technology over the past two centuries has brought about the rise of, and adoptions of new ways of doing things. This has been brought about by the introduction of the computer, and its Technology, (CAD/CAM and CAF-Computer Aided Design manufacture and fabrication) CGI, (computer generated images) and most recently/ importantly, the invention, adoption and application of the 3D printing technology, which has raised the "dyke" a bit higher for the disciplines of Industrial Design and Engineering. The 3D printing technology is become known as a technique that ensures that 3D objects can be reproduced by a Consumer friendly 3D printer. These printers can produce a plastic like model prototype or look- a-like of the object intended for reproduction as opposed to the traditional printers that only spreads ink across a $2 \mathrm{D}$ surface, a process that attempts to create an illusion of Depth in the third Dimension.

The nuclei or hub of the performance activity that connects Design, the Applied Arts and engineering science to make-up the ephemeral material world are to be found in the attributes that characterizes those two disciplines, and their delivery through a well articulated curriculum and system of industrial design education. An educational system (curriculum) with a well defined philosophical goals, aims and (particulate or) set targets and objectives.

These contrived characteristics, nature and physical (aesthetic) attributes acquired by the given designed object, is reflected/perceived through the "prism" of the context, role and relevance of the aesthetics and Applied Arts content (Constituent) inherent in the designed object's innate morphological make-up. Which is spelt out and mirrored against the emphasis of such a context (action, principles and purpose of design) that is understood therefrom, (relative to such a context). This embodys the thrust, the Nature and Content of Industrial Design, its education and its contextualism viz-a-viz the role and place of the Applied Arts as constituent imperatives in the Design industry, education and practice.

\section{Bibliography}

1. Archer, B. (1974). Design Awareness. Toronto: Thorn Press.

2. Barnwell, M. (2011). Design, Creativity and Culture. New York: Black Dog Pub.

3. Beyer, H. \& Karen, H. (1998). Contextual Design; defining customer centred products/ systems. San Francisco: C.A. Morgan Kaufman Pub.

4. Coelho, A. (Eds.) (2011). Industrial Design-New Frontiers. Retrieved from http//www.intechopen.com/books/industrialDesign-New Frontiers 
5. David, F. W \& Noller, N. (1982). Experimental modeling in Engineering. London: Butterworths Pub.

6. DeRose, K. (2009). The case of contextualism, knowledge, skepticism and context. (vol 1). Oxford: Oxford Universities Press.

7. Devore, P. Maley, D. and Ray, W. (1980). An Interview with three Curriculum Experts. Journal of Man Society and Tech, 9-12.

8. Frynier, J.R.A. (1973). School for Tomorrow. Berkley, California: McCutchen Pub. Corp.

9. Goldschmidt, G. (1991). The dialectics of Visual/Sketching. Journal of Creativity Research, 4.

10. Jencks, C. (2002). New Paradigm in Architecture. Connecticut: Yale University Press.

11. Jonson, B. (2005). Design Ideation: The conceptual Sketch in the Digital Age. Design Studies, 26.

12. Lucie-Smith, E. (2001). History of Industrial Design. Oxford: Pharidon Press.

13. Manea, M. (2015). Towards an Integrated Approach to Arts Curriculum and Pedagogy. Review of Artistic Education, 9/10.

14. Manea, M. (2016). Challenges to understanding curriculum Development: Lessons from a Pedagogy class with Arts Pre-service Student - Teachers. Review of Artistic Education, 11/12, 204-208.

15. Morris, R. (2009). The Fundamentals of Product Design. London: AVA Pub.

16. Noblet, J. (1993). Industrial Design: Reflection of a Century. Paris: Flammarion/APCI Pub.

17. Norman, F. (2002). The design of everyday things. New York: Basic Books Pub.

18. Paulter, A. (1976). Curricula Implications in a Technological World. Journal Man, 234-235.

19. Price, A. W. (2008). Contextuality in Practical Reason. Oxford: Oxford University Press.

20. Roozenburg, J.M, \& Eekels J. (1995). Product Design Fundamentals and Methods of Design. John Wiley and Sons. 